\title{
The Compression Behavior of Undisturbed and Compacted Loess Under the Controlling of Total Suction and Injected Solutions
}

\author{
Tongwei Zhang ${ }^{1 *}$, Zhengjin Hu ${ }^{1}$, Hengxing Lan ${ }^{2,3 *}$, Yongfeng Deng ${ }^{4}$ and Huyuan Zhang ${ }^{1}$ \\ ${ }^{1}$ College of Civil Engineering and Mechanics, Key Laboratory of Mechanics on Disaster and Environment in Western China MOE, \\ Lanzhou University, Lanzhou, China, ${ }^{2}$ School of Geological Engineering and Geomatics, Chang'an University, Xi'an, China, ${ }^{3}$ State \\ Key Laboratory of Resources and Environmental Information System, Institute of Geographic Sciences and Natural Resources \\ Research, Chinese Academy of Sciences, Beijing, China, ${ }^{4}$ School of Transportation, Institute of Geotechnical Engineering, \\ Southeast University, Nanjing, China
}

OPEN ACCESS

Edited by:

Yueren Xu,

China Earthquake Administration,

China

Reviewed by: Yong $\mathrm{He}$,

Central South University, China

Pengju Qin,

Taiyuan University of Technology,

China

*Correspondence:

Tongwei Zhang

ztw@lzu.edu.cn

Hengxing Lan

Lanhx@igsnrr.ac.cn

Specialty section:

This article was submitted to Environmental Informatics

and Remote Sensing,

a section of the journal

Frontiers in Earth Science

Received: 20 November 2021

Accepted: 06 January 2022

Published: 16 February 2022

Citation:

Zhang T, Hu Z, Lan H, Deng Y and Zhang $H$ (2022) The Compression

Behavior of Undisturbed and Compacted Loess Under the Controlling of Total Suction and Injected Solutions.

Front. Earth Sci. 10:818919.

doi: 10.3389/feart.2022.818919
Thousands of square kilometers of habitable land have been created on the Loess Plateau in China. In arid and semi-arid area of Northwest China, the mechanical behavior of structural loess is sensitive to water intrusion and human engineering activities. Meanwhile, the higher water salinity in loess and seasonal variation of ambient humidity are common in this area. Due to different physical and mechanical properties of natural and compacted loess, the impacts of ambient humidity and saline water migration on their deformation are still unclear. This paper developed an oedometer test to investigate the compression behavior of natural and compacted loess under environmental humidity (represented by total suction $\Psi$ ) and injection water salinity (represented by osmotic suction $\Psi_{\pi}$ ) changing. The results showed that the void ratio variation $\Delta e$ of compacted loess (the dry density is $1.8 \mathrm{~g} / \mathrm{m}^{3}$ ) under the impact of total suctions (from 14.01 to $146.23 \mathrm{MPa}$ ) and salinities of injected solution $\left(0.17 \mathrm{~mol} / \mathrm{L} \mathrm{NaCl}, 0.29 \mathrm{~mol} / \mathrm{L} \mathrm{Na}_{2} \mathrm{SO}_{4}\right.$ and distilled water) were under 0.01 . The variation of void ratio for undisturbed loess increased about 8 times with 10 times decreasing of total suction, which was corresponding to the increase of relative humidity $(R H)$. In the stage of solution injection, the deformation of undisturbed loess increased with the $\Psi-\Psi_{\pi}$ increasing, and the differences between different samples reached to nearly 20 times. The mechanism was that the salt inside undisturbed loess would deliquescence when the $R H$ was higher than DRH (Deliquescence Relative Humidity), and the natural structure collapsed. The compression index $C_{c}$ of samples generally decreased with $\Psi-\Psi_{\pi}$, and the compressibility of undisturbed loess was higher. The swelling indices $C_{s}$ of samples slightly decreased with $\Psi-\Psi_{\pi}$, but the variation was not significant. The strainstress relationships of loess can be well described by Duncan-Chang constitutive model. Interestingly, the difference of initial deformation modulus $\Delta E_{\mathrm{s}}$ of two loesses, which represented the structural compression under the coupling of total suction and osmotic suction, linearly related to the $\Psi-\Psi_{\pi}$. The $\Delta \varepsilon_{\max }$ between the structural loess and compacted loess exponential increased with $\Psi-\Psi_{\pi}$. In the engineering practice, the humidity and saline water intrusion should be considered in the long-term behavior of loess in shallow layer.

Keywords: compression behavior, undisturbed loess, compacted loess, total suction, injection solutions 


\section{INTRODUCTION}

In recent years, a large number of land reclamation projects in Loess Plateau are in progress, which located in the arid and semiarid loess area. The loess in Western China is mainly a kind of silty clays, and the groundwater frequently composed of sodium sulfate and sodium chloride. The structural loess is easy to collapse under water intrusion. In the land reclamation area, the different physical properties of compacted and undisturbed loess will lead to uneven settlement near the interface of filling and excavating area. Under the coupling effect of water infiltration (rainfall, irrigation and groundwater migration) and human engineering activities, the mechanical properties of loess deteriorated. Especially, the climate changing leads to environmental humidity change. In the engineering practice, it is doubtful that the humidity and saline water intrusion should be considered in the long-term behavior of loess in shallow layer $(\mathrm{Ng}$ and Pang, 2000; Zhang et al., 2013; Daliakopoulos et al., 2016; Chen et al., 2017; Ivushkin et al., 2019).

The water chemistry effects on the compression behavior of soil has been drawn an extensive attention. Lu et al. (2020) (Zuo et al., 2020) indicated that the migration of groundwater will lead to the decrease of ion concentration of pore water, the decrease of bonding strength and the collapse of loess structure. Wen et al. (2014) (Wen and Yan, 2014) considered that the soluble salts existed on the surface of soil particles play a role of skeleton and cementation. Niu et al. (2021) (Niu and Yao, 2021) revealed that the elastic modulus of soil decreased after multiple drying-wetting cycles. Zhang et al. (2019) (Zhang and Wang, 2019) adopted the osmotic suction to characterize the chemical effects of pore water, and investigated its influences on the compression and permeability characteristics of remolded clay. Amir et al. (2018) (Amir Akbari et al., 2018) reported that the saline water infiltration significantly influenced the hydraulic characteristics of unsaturated soil in the subgrade of highway, and resulted in the collapse of soil. The reason was that the matrix suction changed with the environmental humidity.

The particular structure and water sensitivity of loess are the main factors of subgrade settlement. In practice, compaction has been frequently used to improve the strength of soil and bearing capacity of foundation. The water sensitivity of compacted loess is closely related to their mineralogy and microstructure (Ma et al., 2016). During compression, the moisture content of compacted loess increased by $4.4-7.4 \%$ ( $\mathrm{Mu}$ et al., 2020). Then, there are some differences of the structure and water sensitivity between undisturbed and compacted loess. Recently, based on the development of unsaturated soil theory and test methods, there have been many valuable achievements in the study of compression behavior of loesses. Chang et al. (2020) (Chang et al., 2020) conducted consolidation and drainage triaxial shearing tests on undisturbed $\mathrm{Q}_{3}$ loess and undisturbed $\mathrm{Q}_{2}$ loess in Yan'an New Area. The results explored that the matrix suction controlled the strength and initial Young's modulus of unsaturated loess. Lan et al. (2021) (Lan et al., 2021) found that the cyclic expansion and contraction of loess slope correlated to the changes of humidity and temperature and established a prediction model. Qin et al. (2020) (Qin et al., 2020) indicated that the structural properties of unsaturated and saturated loesses during compression exhibited different trend and the anisotropy of samples tend to be stable as vertical strain increases. Besides of studies on loess, Deng et al. (2018) (Deng et al., 2018) pointed out the mineralogy of saturated remolded soil was the key factor controlling pore water salinity effects on their compression and permeability. Miller et al. (2006) (Debora and Miller, 2006) found that the osmotic suction should be considered in the matrix suction measurement, and the matrix suction was not proper to replace the total suction in unsaturated soil with high salinity. $\mathrm{He}$ et al. (2020) (He et al., 2020) studied the swelling and shrinkage characteristics of compacted GMZ bentonite by varying the concentration of $\mathrm{NaCl}$ solution and total suction. Results showed that the sample saturated with salt solution has a higher degree of saturation than the sample saturated with distilled water for a given total suction.

In summary, many researchers paid attention on the salinity, moisture content and micro-structure effects on mechanical properties of different soils (Loret et al., 2002; Debora and Miller, 2006; Koniorczyk and Gawin, 2008; Zhang et al., 2016; Elkady and Al-Mahbashi, 2017; Jabar and Rasul, 2017; Sato and Hattanji, 2018; He et al., 2020; Wang et al., 2020). While, few studies focus on the response of compression behavior of undisturbed loess and remolded loess to the environmental humidity change and saline water intrusion in the northwest arid and semi-arid areas. This paper aimed to reveal the different performance of engineering properties of remodeling and undisturbed loess under extreme climate and human activities. Then, a modified one-dimensional consolidation test with controlling humidity and intruded water salinity was developed. The compression behavior of undisturbed and remolded loess under the coupling of loading, total suction and osmotic suction were investigated. The results will provide a reference for the evaluation of long-term behavior of land reclamation project in Western China.

\section{MATERIALS}

The undisturbed loess was sampled at a depth of $1 \mathrm{~m}$ from the excavation area of a land reclamation site in Lanzhou New Area, Gansu Province. The basic physical properties of soil were determined according to Chinese standard GB/T 50,123-2019 for geotechnical tests. As shown in Table 1, the initial void ratios of natural loess and compacted loess were 1.14 and 0.53 respectively. The differences of permeability coefficient between these two loesses were 10 times. The particle size distribution of fine particles based on laser analysis is shown in Figure 1. The XRD pattern shown in Figure 2 indicates that the main clay minerals are illitesmectite mixed layer and kaolinite. The $\mathrm{KCl}, \mathrm{MgCl}_{2}, \mathrm{Ki}$, $\mathrm{ZnSO}_{4}, \mathrm{~K}_{2} \mathrm{CO}_{3}$ and $\mathrm{Na}_{2} \mathrm{SO}_{4}$ were used to prepare saturated salt solution. Meanwhile, sodium chloride $(\mathrm{NaCl})$ and sodium sulfate $\left(\mathrm{Na}_{2} \mathrm{SO}_{4}\right)$ solutions with $0.17 \mathrm{~mol} / \mathrm{L}$ and $0.29 \mathrm{~mol} / \mathrm{L}$ were prepared respectively. The selected salinities were according to the in-situ investigation on loesses in Lanzhou New Area. 
TABLE 1 | Physical properties of selected loess.

\begin{tabular}{|c|c|c|c|c|c|c|c|c|}
\hline Types & $\begin{array}{l}\text { Natural } \\
\text { water } \\
\text { content } \\
(\%)\end{array}$ & $\begin{array}{c}\text { Specific } \\
\text { gravity }\end{array}$ & $\begin{array}{l}\text { Natural } \\
\text { density } \\
\left(\mathrm{g} / \mathrm{cm}^{3}\right)\end{array}$ & $\begin{array}{c}\text { Dry } \\
\text { density } \\
\left(\mathrm{g} / \mathrm{cm}^{3}\right)\end{array}$ & $\begin{array}{l}\text { Void } \\
\text { ratio }\end{array}$ & $\begin{array}{c}\text { Liquid } \\
\text { limits } \\
(\%)\end{array}$ & $\begin{array}{c}\text { Plastic } \\
\text { limits } \\
(\%)\end{array}$ & $\begin{array}{c}\text { Permeability } \\
\text { coefficient } \\
\text { (cm/s) }\end{array}$ \\
\hline $\begin{array}{l}\text { Excavation } \\
\text { area }\end{array}$ & 3.7 & 2.73 & 1.32 & 1.2 & 1.14 & 26.18 & 16.83 & $2.5 \times 10^{-4}$ \\
\hline Filling area & 12.3 & 2.73 & 2.00 & 1.8 & 0.53 & 26.18 & 16.83 & $2.1 \times 10^{-5}$ \\
\hline
\end{tabular}

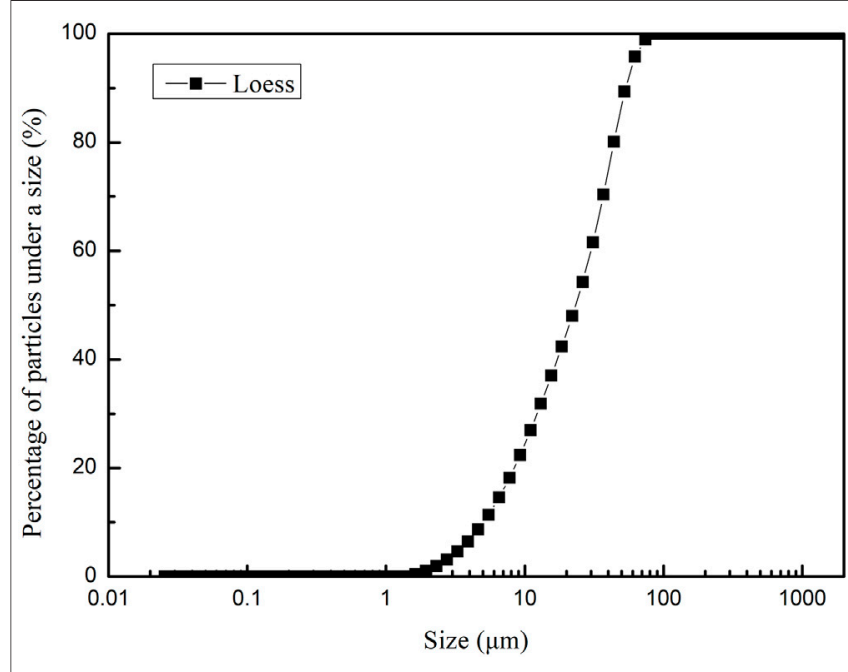

FIGURE 1 | Particle size distribution of selected loess.

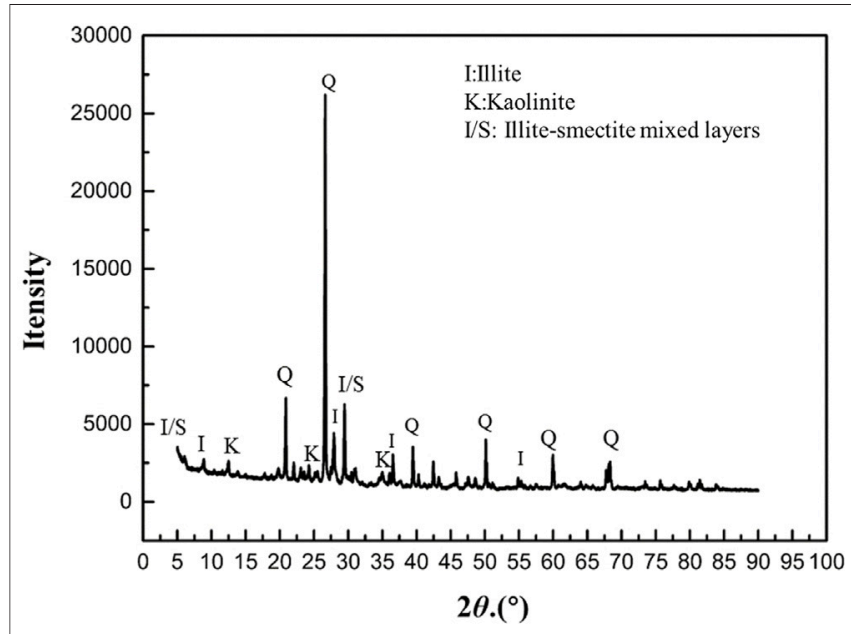

FIGURE 2 | The mineralogy of loess in Lanzhou New Area.

\section{METHODS}

\section{Sample Preparing}

For the undisturbed loess, the samples with a height $20 \mathrm{~mm}$ and diameter $61.8 \mathrm{~mm}$ were prepared by cutting the intact soil in field.
Then, they were air dried or titrated to a uniform moisture content $3.7 \%$, and sealed for $24 \mathrm{~h}$ to reach a homogenous state. For the compacted samples, the remolded loess was statically compressed in the steel ring with a height $20 \mathrm{~mm}$ and diameter $61.8 \mathrm{~mm}$ according to the physical indexes of compacted loess shown in Table 1.

\section{Modified Oedometer Tests}

The set-up of modified oedometer tests mainly included a sealed container filling with saturated solution, a peristaltic cycling pump and a loading system. As shown in Figure $\mathbf{3 A}$, the vapor of saturated solution was circularly pumped (the speed was $20 \mathrm{rpm}$ ) to the top and bottom of installed sample. Besides, the saturated solution was also filled in the container to obtain the homogenization of total suction or humidity in samples. The samples were not allowed to be contaminated with saturated solution in the container. Figure $\mathbf{3 B}$ presented the scheme of solution injection stage of the compression tests. In this stage, the $0.17 \mathrm{~mol} / \mathrm{L} \mathrm{NaCl}$ and $0.29 \mathrm{~mol} / \mathrm{L} \mathrm{Na}_{2} \mathrm{SO}_{4}$ were circularly pumped to soak the bottom of samples.

The osmotic suction and total suction controlled compression tests were performed following these procedures:

1) The loading of 12.5 and $25 \mathrm{kPa}$ were applied to the undisturbed and remolded loess following Chinese standard GB/T 50,123-2019, and each step of loading last for $24 \mathrm{~h}$.

2) Under the load of $25 \mathrm{kpa}$, the vapor of saturated solution was circularly pumped to samples for reaching the equilibrium of relative humidity as shown in Figure 3A. The period of this stage was about 7 days, which was based on the ending of deformation development.

The total suction includes matrix suction and osmotic suction, and normally correlated to the relative humidity in soil. In this test, the saturated solution was used to provide a certain relative humidity in the sealed container. According to thermodynamics, the relationship between the total suction and the relative humidity of the saturated solution was expressed as follows:

$$
\psi=\frac{R T \rho_{w}}{W} \ln \left(\frac{1}{R H}\right)
$$

Where $\Psi$ is the total suction in $\mathrm{kPa} ; R$ is molar gas constant, $8.3145 \mathrm{~J} /(\mathrm{mol} \cdot \mathrm{K}) ; \rho_{\mathrm{w}}$ is the density of water, $\mathrm{kg} / \mathrm{m}^{3} ; W$ is the molar mass of water vapor, $18.016 \mathrm{~g} / \mathrm{mol} ; T$ is the absolute temperature in $\mathrm{K} ; R H$ is relative humidity, $\%$. 

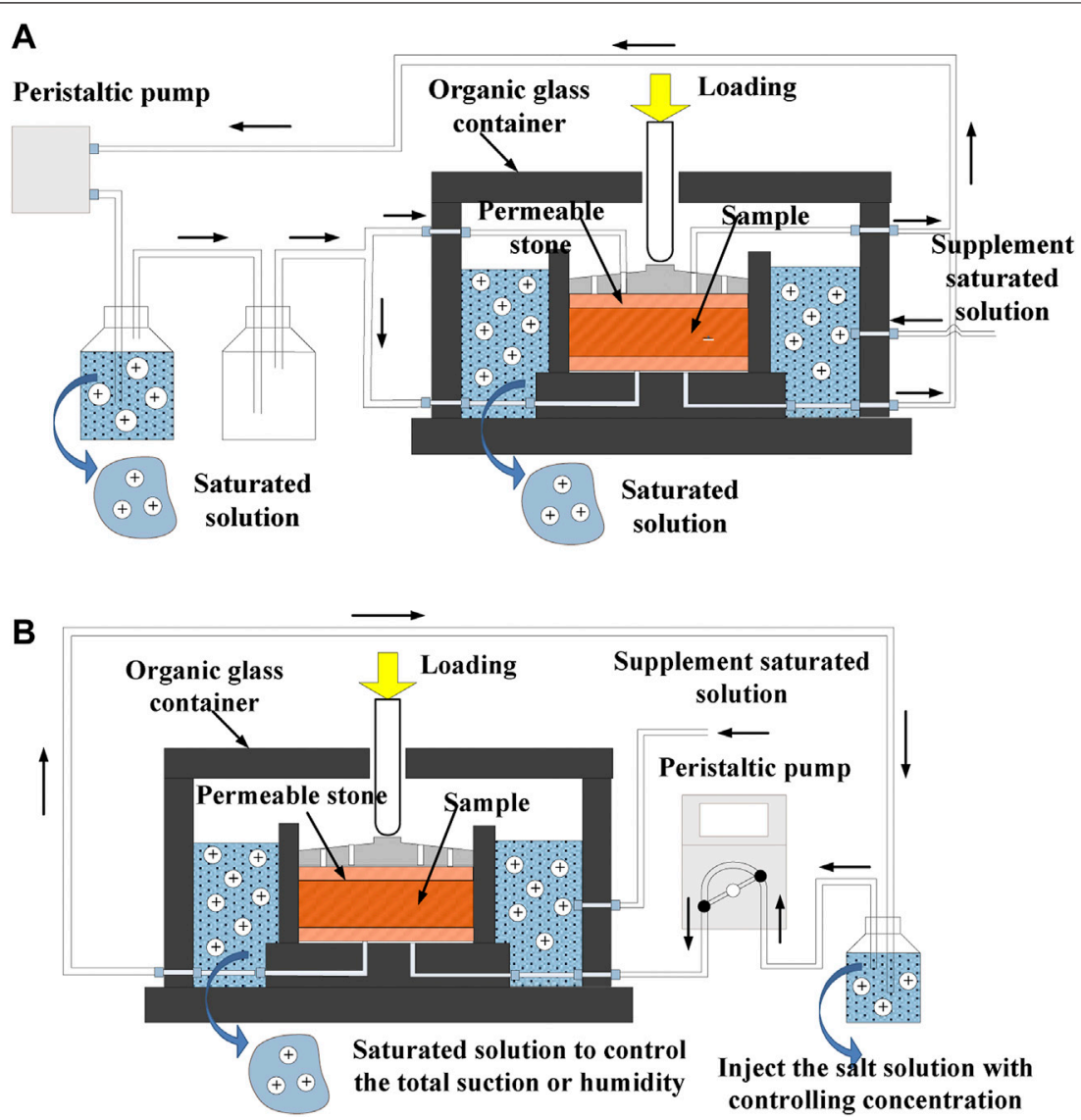

FIGURE 3 | The schematic diagram of modified oedometer tests with controlling total suction and injected solutions: (A) The set-up of total suction controlling device; (B) The set-up of solution injection device.

\begin{tabular}{lcc}
\hline TABLE 2 | The total suction and $\mathrm{RH}$ of saturated solution $\left(15^{\circ} \mathrm{C}\right)$. & \\
\hline Solution & $\mathbf{R H}(\%)$ & $\boldsymbol{\Psi ( \mathbf { M P a } )}$ \\
\hline Saturated $\mathrm{MgCl}_{2}$ & 33.3 & 146.23 \\
Saturated $\mathrm{KCl}$ & 86 & 20.06 \\
Saturated $\mathrm{ZnSO}_{4}$ & 90 & 14.01 \\
Saturated $\mathrm{KI}$ & 71 & 45.55 \\
Saturated $\mathrm{Na}_{2} \mathrm{SO}_{4}$ & 96 & 11.09 \\
Saturated $\mathrm{K}_{2} \mathrm{CO}_{3}$ & 43.5 & 110.70 \\
\hline
\end{tabular}

The tests were performed at $15^{\circ} \mathrm{C}$, and the relative humidity and calculated total suction corresponding to various saturated salt solutions are shown in Table 2 .

3) When the vertical deformation was unchanged at stage (2), replace the experimental set-up to control the osmotic suction of inject solution as shown in Figure 3B. The samples were soaked with $\mathrm{NaCl}$ at a mass content of $1 \%$, $\mathrm{Na}_{2} \mathrm{SO}_{4}$ at a mass content of $4 \%$ and distilled water. Meanwhile, we recorded the vertical deformation of soil under saline water infiltration. The period of solution soaking was maintained to $24 \mathrm{~h}$.
Witteven et al. (2013) (Witteveen et al., 2013) experimentally studied the influences of $\mathrm{NaCl}$ solution on the suction of illite clay. The results showed that osmotic suction of soil- $\mathrm{NaCl}$ mixtures and $\mathrm{NaCl}$ solution identified by filter paper method were close, which indicated that the clay minerals almost had negligible influences on the measured osmotic suction. Then, the controlling osmotic suction in soil can be considered as the osmotic suction of injected saline water. Metten 1966) (Wang et al., 2020) proposed that the osmotic suction can be calculated by Van Hoff equation as following:

$$
\psi_{\pi}=v R T c
$$

Where $\Psi_{\pi}$ represents osmotic suction, $\mathrm{kPa} ; v$ is the number of ionizable ion, such as $\mathrm{NaCl}$ solution $v=2 ; R$ is gas constant, $R=$ $8.3145 \mathrm{~J} / \mathrm{mol} \cdot \mathrm{K} ; T$ is absolute temperature, $K$; $c$ represents molar concentration of solution $(\mathrm{mol} / \mathrm{L})$. The relationship between molar concentration and mass concentration is $c=1000 \omega \rho / M$, where $\omega$ represents the mass concentration, $\rho$ is the density of water in $\mathrm{g} / \mathrm{cm}^{3}$, and $M$ is the molar mass of the solute. Table 3 gives the calculated osmotic suction of $1 \%$ sodium chloride $(\mathrm{NaCl})$ solution, $4 \%$ sodium sulfate $\left(\mathrm{Na}_{2} \mathrm{SO}_{4}\right)$ solution and distilled water based on eq. (Ivushkin et al., 2019). 
TABLE 3 | The osmotic suction of selected solution for soaking soil $\left(15^{\circ} \mathrm{C}\right)$.

\begin{tabular}{lccc}
\hline Saline solution & Ion number $\boldsymbol{v}$ & $\begin{array}{c}\text { Molar } \\
\text { concentration } \boldsymbol{c} \text { (mol/L) }\end{array}$ & Osmotic suction $\Psi_{\pi}(\mathbf{M P a})$ \\
\hline $1 \% \mathrm{NaCl}_{\text {solution }}$ & 2 & 0.17 & 0.74 \\
$4 \% \mathrm{Na}_{2} \mathrm{SO}_{4}$ solution & 2 & 0.29 & 1.39 \\
Distilled water & 0 & 0 & 0
\end{tabular}

4) After the deformation was stable in the soaking stage, the conventional consolidation tests were carried out under the loading from 25 to $1,600 \mathrm{kPa}$, and then unload to $25 \mathrm{kPa}$ step by step. The loading increment or decrement followed a ratio of $1: 2$ or $2: 1$, and the loading or unloading period would last for $24 \mathrm{~h}$. Based on the $e$ - $\lg p$ curves of each sample, the total suction and osmotic suction effects on the compression coefficient, compression index and other mechanical behavior of compacted and undisturbed loess were discussed.

\section{RESULTS AND DISCUSSIONS}

\section{The Compression Curves e-Igp}

Figure 4A-C presented the $e$-lg $p$ curves of undisturbed loess with vary controlling environmental humidity and salinities. The results showed that the structure of undisturbed loess significantly collapsed under the coupling of total suction and osmotic suction at the $25 \mathrm{kPa}$, and the compression indices changed after $25 \mathrm{kPa}$. In Figure $4 \mathrm{~A}$, the variation of void ratio $\Delta e$ at $25 \mathrm{kPa}$ reached to about 0.10 under $\Psi=146.23 \mathrm{MPa}$ and $\Psi_{\pi}$ $=0.74 \mathrm{MPa}$ for undisturbed loess, while it significantly decreased to about 0.035 under $\Psi=20.06 \mathrm{MPa}$ and $\Psi_{\pi}=0.74 \mathrm{MPa}$. It indicated that the volume of collapse increased with the total suction for a critical osmotic suction. After $25 \mathrm{kPa}$, the slope of $e$-lg $p$ curve under $\Psi=146.23 \mathrm{MPa}$ and $\Psi_{\pi}=0.74 \mathrm{MPa}$ was lower than that under $\Psi=20.06 \mathrm{MPa}$ and $\Psi_{\pi}=0.74 \mathrm{MPa}$. In Figure 4B, the collapsed volume of samples under $\Psi=45.55 \mathrm{MPa}$ and $\Psi_{\pi}=$ $1.39 \mathrm{MPa}$ were larger than that under $\Psi=14.01 \mathrm{MPa}$ and $\Psi_{\pi}=$ $1.39 \mathrm{MPa}$ at $25 \mathrm{kPa}$. While, it is interesting that their slopes in $e-\lg p$ curves were close for the approximately close total suction (the difference was within one order of magnitude). In Figure 4C, the $\Delta e$ of undisturbed samples at $25 \mathrm{kPa}$ under $\Psi=110.7 \mathrm{MPa}$ and $\Psi_{\pi}=0 \mathrm{MPa}$ was higher than that under $\Psi=11.09 \mathrm{MPa}$ and $\Psi_{\pi}=0 \mathrm{MPa}$, and the changes of compression indices presented a similar trend which the compression index of samples under $\Psi=$ $11.09 \mathrm{MPa}$ and $\Psi_{\pi}=0 \mathrm{MPa}$ was higher.

Figure 5A-C presented the $e$-lg $p$ curves of remolded loess, being at a consistent compacted dry density $1.8 \mathrm{~g} / \mathrm{cm}^{3}$ and compressed under vary controlling environmental humidity and salinities. Being different with undisturbed samples, the volume changes $\Delta e$ at $25 \mathrm{kPa}$ decreased with total suction $\Psi$ increasing for $\Psi_{\pi}=1.39 \mathrm{MPa}, \Psi_{\pi}=0.74 \mathrm{MPa}$ and $\Psi_{\pi}=0 \mathrm{MPa}$. After $25 \mathrm{kPa}$, the slopes in $e$-lg $p$ curves of compacted loess were not significantly influenced by environmental humidity, and they seemed to be close under an identical $\Psi_{\pi}$. Generally, the final volume changes $\Delta e$ of samples with lower total suction $\Psi$ at $1,600 \mathrm{kPa}$ was higher than that of samples with larger total suction $\Psi$ for an identical $\Psi_{\pi}$. The differences of final void ratio in two compression curves of each figure were about 0.1 . Meanwhile, the impact of total suction and osmotic suction on the collapsed volume of compacted loess significantly decreased comparing to undisturbed loess.

\section{The Volume Change With Elapsed Time at $25 \mathrm{kPa}$}

To compare the deformation of undisturbed loess and compacted loess at different stages, the void ratio $e$ changed with elapsed time $T$ (s) were illustrated in Figure 6. The stages included an applied loading of $25 \mathrm{kPa}$ (I), total suction equilibrium (II) and saline water injection (III).

As shown in Figure 6A, the primary compression at $25 \mathrm{kPa}$ of undisturbed loess was about 6 times larger than that of compacted loess, which indicated a higher compressibility of structural loess with an initial void ratio larger than 1.0. At the stage of total suction equilibrium, the secondary consolidation settlement $\Delta e$ of undisturbed and compacted loess were 0.009 and 0.003 . When the samples soaked in the solution with osmotic suction equal to $0.74 \mathrm{MPa}$, the compacted soil collapsed from $e=0.485$ to $e=0.47$, and the $\Delta e$ of undisturbed loess was only 0.004 . In Figure 6B, the volume change of undisturbed loess was about 9 times larger than that of compacted loess at the first stage. Then, the creeping deformation of undisturbed loess was also 5 times than compacted loess at the second stage, but their $\Delta e$ were both under 0.01 . Under the coupling of $\Psi=146.23 \mathrm{MPa}$ and $\Psi_{\pi}=$ $0.74 \mathrm{MPa}$, the volume contraction of undisturbed soil significantly larger than compacted samples, being different with the results shown in Figure 6A

In Figure 6C,D, the larger primary compression of undisturbed loess under $25 \mathrm{kPa}$ applied was confirmed. The difference of the long-term creeping of two soil was within 10 times under $\Psi=14.01 \mathrm{MPa}$ and $\Psi=45.55 \mathrm{MPa}$ which were less than $100 \mathrm{MPa}$. At the third stage, the collapsed volume of undisturbed loess were about 2 times higher than that of compacted loess in the case of $\Psi_{\pi}=1.39 \mathrm{MPa}$.

In Figure 6E,F, the $\Delta e$ of undisturbed loess were from 0.03 to 0.06 and that of compacted loess was about $0.01-0.02$ at the first stage. Under the higher controlling total suction $\Psi=110.7 \mathrm{MPa}$, the creeping void ratio decrement of two soils were within 0.01 . While the void ratio variations of undisturbed loess and compacted loess were 0.03 and 0.008 in the condition of lower total suction $\Psi=11.09 \mathrm{MPa}$ which corresponding a $R H=96 \%$. When the distilled water induced, the void ratio of undisturbed loess decreased 0.013 and 0.005 in the condition of $\Psi=110.7 \mathrm{MPa}$ and $\Psi=11.09 \mathrm{MPa}$ respectively. At this stage, the volume of 

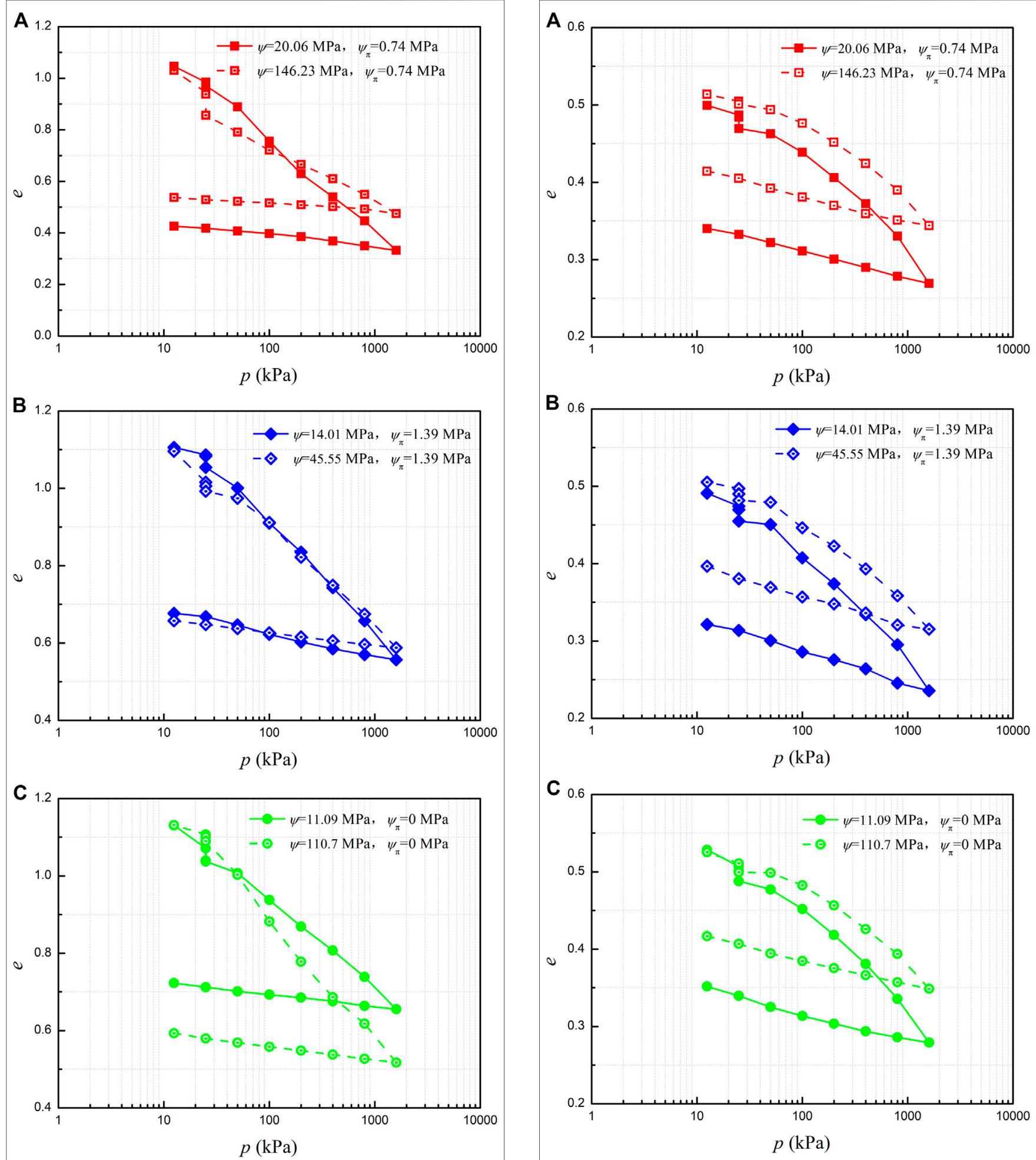

FIGURE 4 | The e-lgp curves of undisturbed loess under total suction and osmotic suction: (A) $\Psi_{\pi}=0.74 \mathrm{MPa}$; (B) $\Psi_{\pi}=1.39 \mathrm{MPa}$; (C) $\Psi_{\pi}=0 \mathrm{MPa}$.

FIGURE $\mathbf{5}$ | The e-lgp curves of compacted loess under total suction and osmotic suction: (A) $\Psi_{\pi}=0.74 \mathrm{MPa}$; (B) $\Psi_{\pi}=1.39 \mathrm{MPa}$; (C) $\Psi_{\pi}=0 \mathrm{MPa}$. 


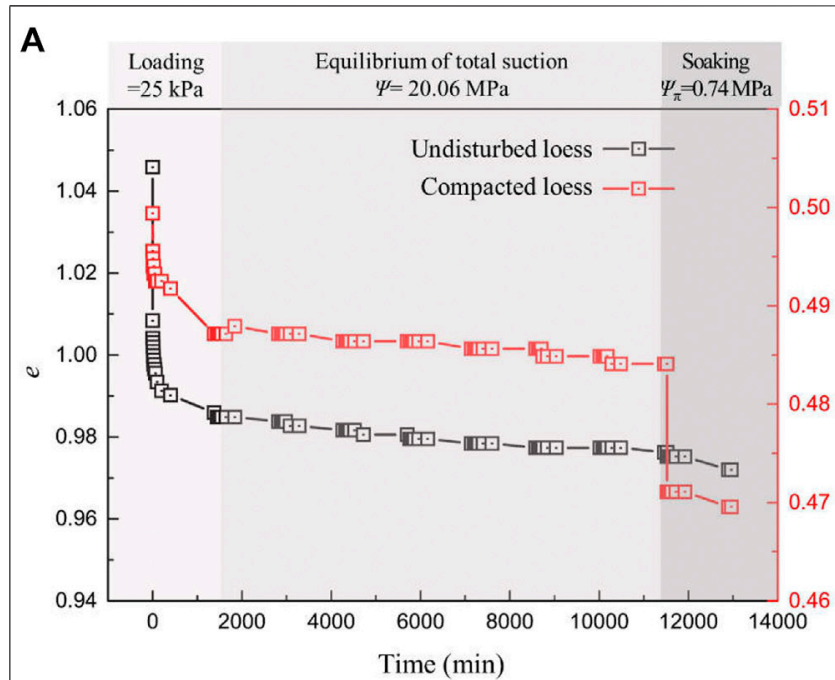

B

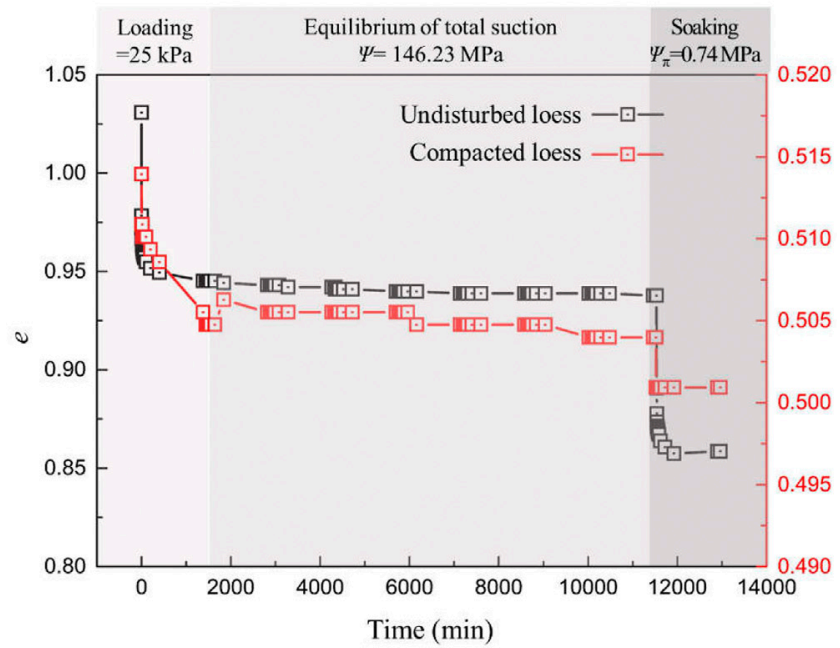

C

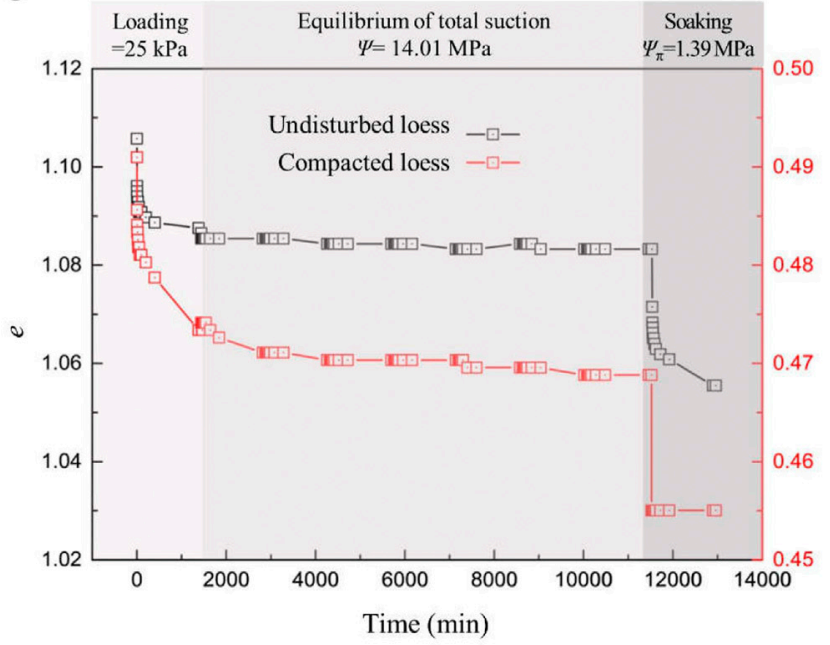

FIGURE 6 | The e-Time curves of undisturbed and compacted loess under impact of total suction and osmotic suction: (A) $\Psi=20.06 \mathrm{MPa}$ and

(Continued)
FIGURE 6 $\Psi_{\pi}=0.74 \mathrm{MPa}$; (B) $\Psi=146.23 \mathrm{MPa}$ and $\Psi_{\pi}=0.74 \mathrm{MPa}$; (C) $\Psi=$ $14.01 \mathrm{MPa}$ and $\Psi_{\pi}=1.39 \mathrm{MPa}$; (D) $\Psi=45.55 \mathrm{MPa}$ and $\Psi_{\pi}=1.39 \mathrm{MPa}$; (E) $\Psi=11.09 \mathrm{MPa}$ and $\Psi_{\pi}=0 \mathrm{MPa} ;(\mathbf{F}) \Psi=110.7 \mathrm{MPa}$ and $\Psi_{\pi}=0 \mathrm{MPa}$.

compacted loess decreased 0.002 and 0.011 for $\Psi=110.7 \mathrm{MPa}$ and $\Psi=11.09 \mathrm{MPa}$ respectively. Generally, the primary compression of samples under a constant loading $25 \mathrm{kPa}$ were controlled by the initial structure and void ratio. Then, the volume changes of primary consolidation of structural loess were higher than that of compacted loess. While, with the $R H$ changing and saline water induced, the collapses of loess were significant. Figure 7A summarized the void ratio decrement $\Delta e$ varied with total suction $\Psi$ at the second stage. To characterize the coupling effect of $\Psi$ and $\Psi_{\pi}$ on the collapse of loess, the relationships between $\Delta e$ and $\Psi-\Psi_{\pi}$ were presented in Figure 7B.

As shown in Figure 7A, the results indicated that creeping deformation of undisturbed loess significantly decreased with total suction increasing which corresponding to relative humidity decreasing. When the $R H<90 \%$, the $\Delta e$ at secondary consolidation stage were lower than 0.01 . While, the $\Delta e$ reached to 0.03 when the $R H=96 \%$. For the compacted loess, the $\Delta e$ at secondary consolidation stage were all lower than 0.01 and the media value was 0.005 , which seemed to be irrelevant to environmental humidity.

When the solution was induced, the collapse of undisturbed loess increased from 0.005 to 0.08 with the $\Psi-\Psi_{\pi}$ increasing as indicated in Figure 7B. The highest difference between the samples was nearly 20 times. The higher $\Psi-\Psi_{\pi}$ resulted in a higher solution inducing collapse. While, the volume changes of compacted loess decreased with $\Psi-\Psi_{\pi}$ increasing, and that of all samples were under 0.015 .

Therefore, the creeping in high environmental humidity and the collapse under saline water intrusion being high $\Psi-\Psi_{\pi}$ for loess would be considered for the shallow layer, especially the uneven settlements between undisturbed loesses and compacted loesses. For the undisturbed loesses, higher relative humidity resulted in higher creeping without considering water intrusion. Under the groundwater intrusion, the dry loess with higher $\Psi-\Psi_{\pi}$ would collapsed dramatically. For the compacted loesses, the creeping seemed to be irrelevant to environmental humidity without considering water intrusion. When saline water induced, a higher collapse of wet loess with lower $\Psi-\Psi_{\pi}$ occurred.

\section{The Compression Parameters}

The compressibility index of soil based on $e$-lg $p$ curves is the fundamental parameters to investigate the soil settlement. The compression index $C_{\mathrm{c}}$ is the slope of the straight section in $e-\lg p$ curve after yielding of soil, and the swelling index $C_{\mathrm{s}}$ the slope of the $e-\lg p$ curve in the unloading stage. Previous studies revealed that the compression index of saturated montmorillonite clay significantly decreased with the increase of osmotic suction and then tend to be constant (Deng et al., 2018; He et al., 2020). In this study, the relationships between the compression index of unsaturated loess and osmotic suction under the changing of ambient humidity represented by total suction were considered. 


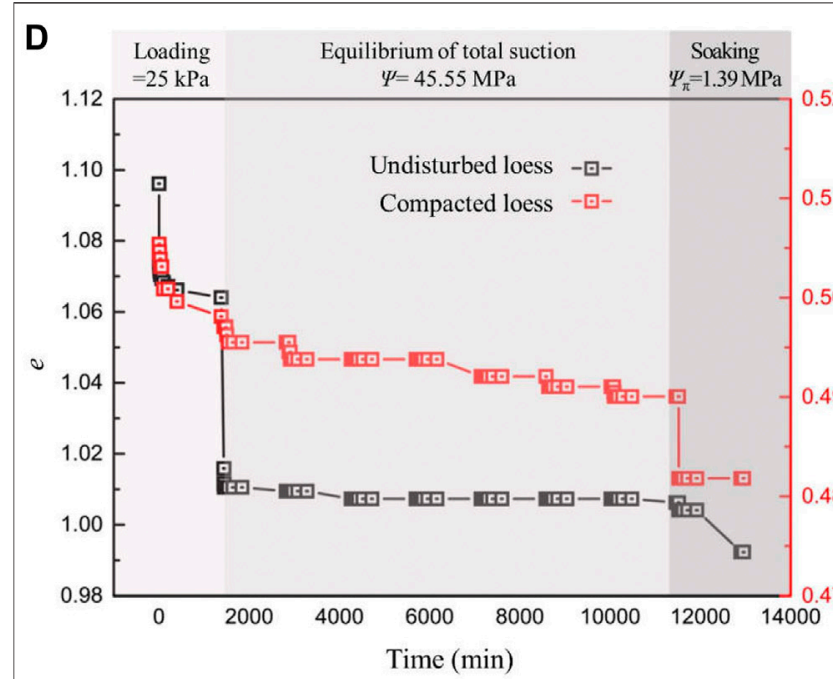

E

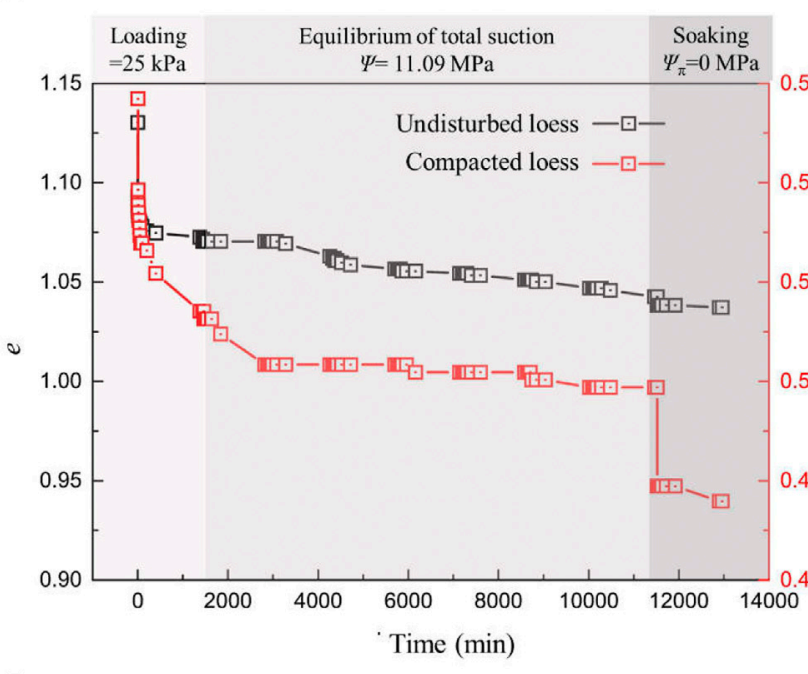

F

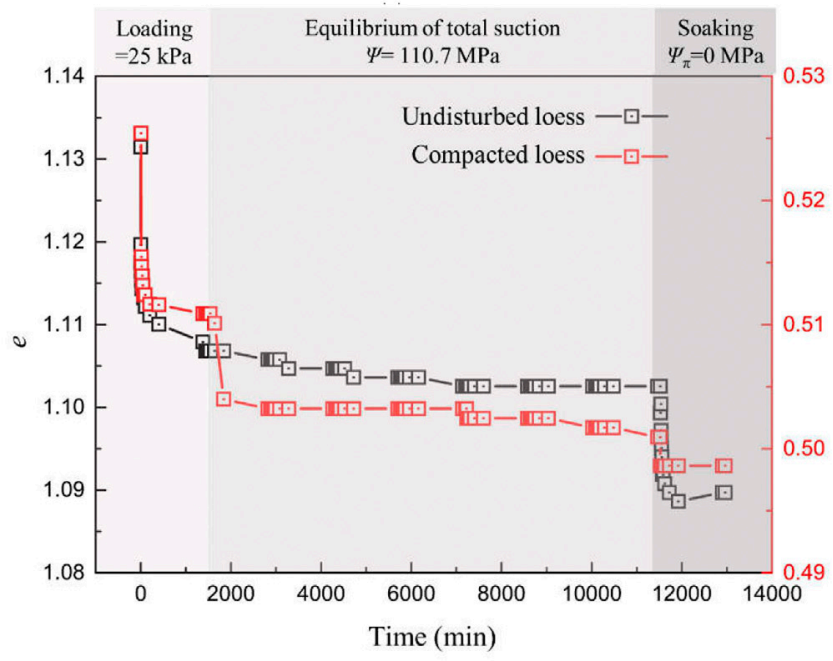

FIGURE 6 | (continued).
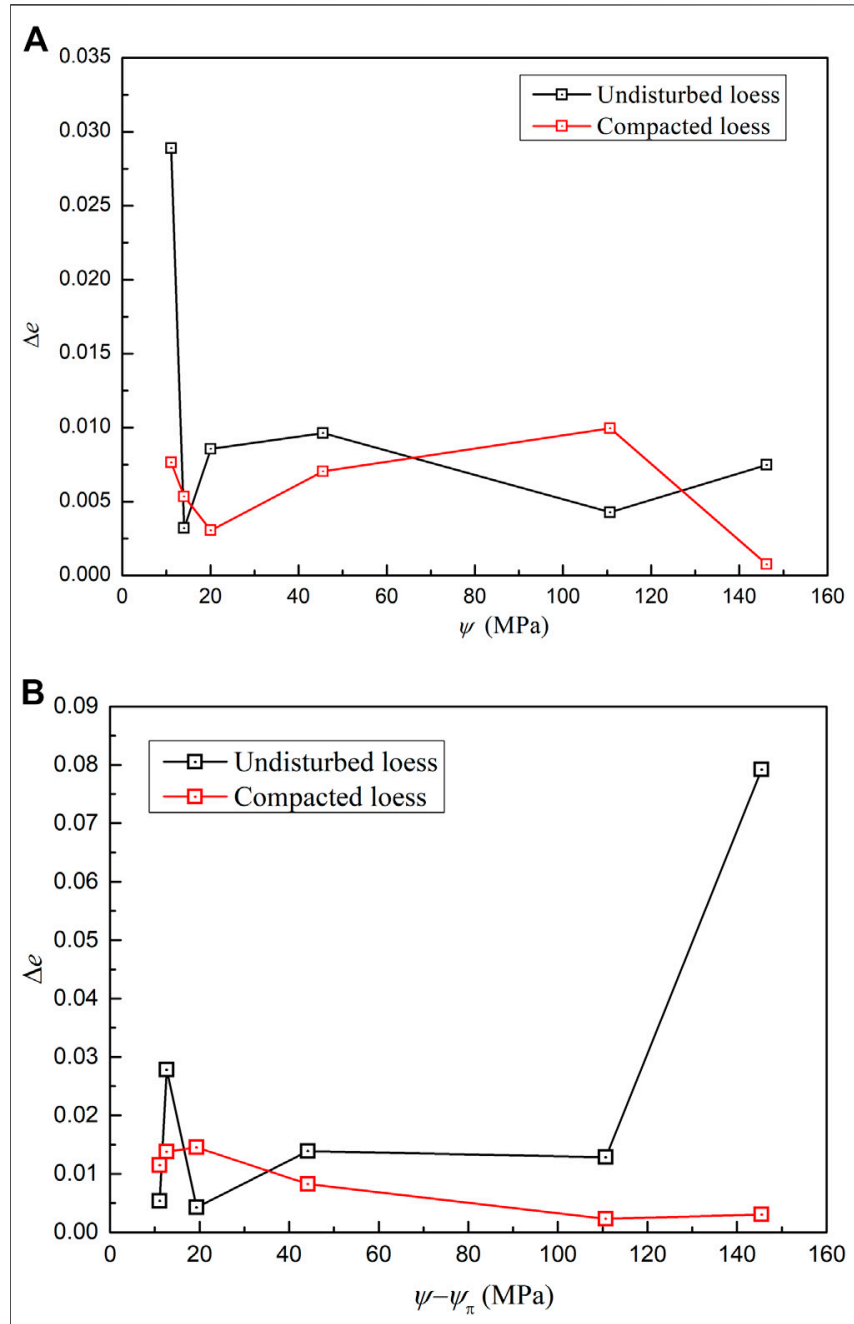

FIGURE 7| The $\Delta$ e under impact of total suction and osmotic suction: (A) the $\Delta$ e versus $\Psi$ at the second stage; (B) the $\Delta$ e versus $\Psi-\Psi_{\pi}$ at the third stage.

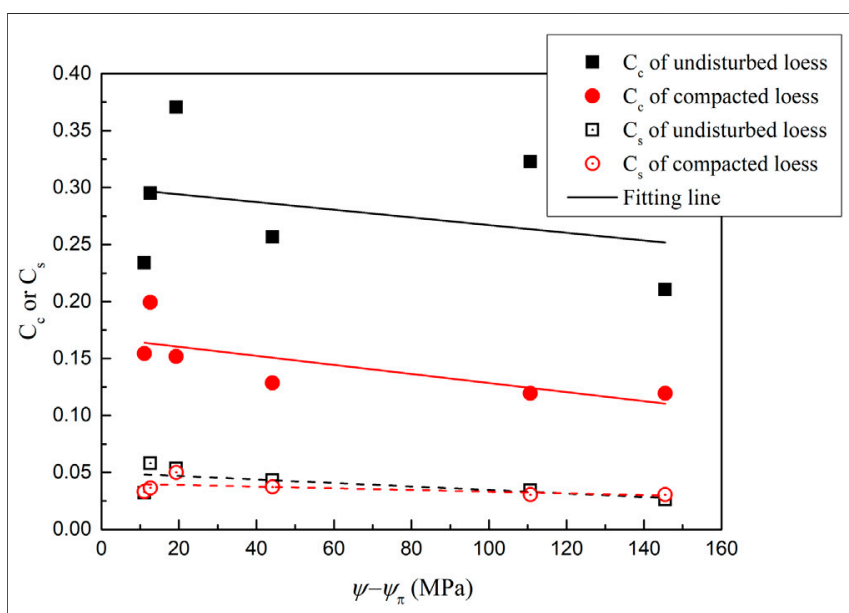

FIGURE 8 | The compression index $C_{\mathrm{c}}$ and swelling index $C_{\mathrm{s}}$ versus $\Psi-\Psi_{\pi}$ 


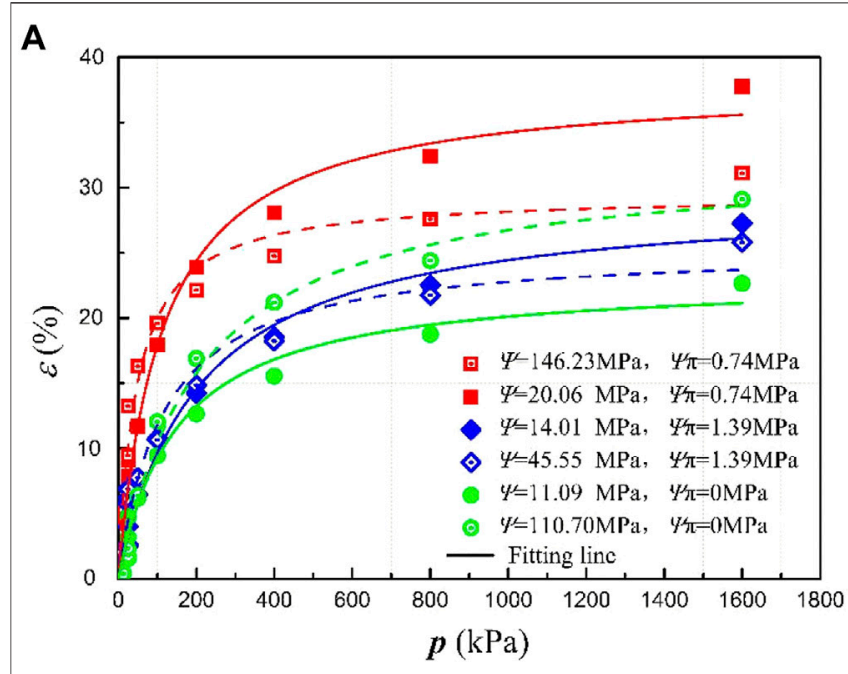

B

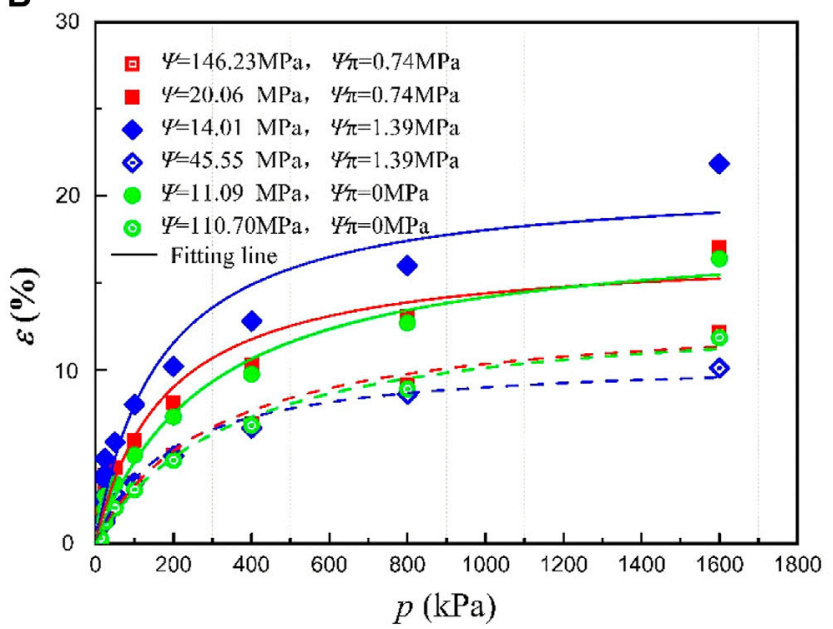

FIGURE 9 | The strain-stress relationships of samples: (A) undisturbed loess; (B) compacted loess.

As mentioned, the coupling effects of ambient humidity and saline water intrusion on soil settlement were expressed as the relationships between compressibility index and $\Psi-\Psi_{\pi}$. The results plotted in Figure 8 showed that the compression index $C_{\mathrm{c}}$ of samples generally decreased with $\Psi-\Psi_{\pi}$, and the compressibility of undisturbed loess was higher. The swelling indices $C_{\mathrm{s}}$ of samples also decreased with $\Psi-\Psi_{\pi}$, but the variation was not significant as $C_{\mathrm{c}}$. The reason is that the swelling of loess is mainly attributed to the elastic deformation of particles. Unlike the montmorillonite soil, water molecule can not go into interlayer of kaolinite or illite and result in soil expansion. Then, the variation of $C_{s}$ was not significant.

In terms of compression, the responses of undisturbed and remolded loess to environmental humidity and water salinity were different. When the $\Psi-\Psi_{\pi}$ reached to $40 \mathrm{MPa}$, the compression index of remolded loess was almost constant. The $\Psi-\Psi_{\pi}$ of undisturbed loess significantly fluctuated after $40 \mathrm{MPa}$. The maximum $C_{\mathrm{c}}$ and $C_{\mathrm{s}}$ of samples corresponded to the $\Psi-\Psi_{\pi}$ being 10-20 MPa. The reason for the higher $C_{\mathrm{c}}$ of undisturbed and remolded loess under higher humidity is that the micro pores in soil absorbed water and moisture content increased. The soil cementation was hydrated resulting in large compressibility of structural loess (Sato and Hattanji, 2018; Wei et al., 2020; Xu et al., 2020). Meanwhile, the sodium sulfate in soil would form hydrated crystals in the process of humidity increasing. It lead to the expansion of soil and the reduction of compressibility (Zhang et al., 2012; Langlet et al., 2013).

The stress-strain relationships of undisturbed and remolded loess were further discussed by elastoplastic model. Among the constitutive models, Duncan Chang model has been widely used in engineering practice. Based on that, the hyperbolic model was also used to describe the one-dimensional stress-strain relationships of soil under confining conditions. The function can be expressed as following:

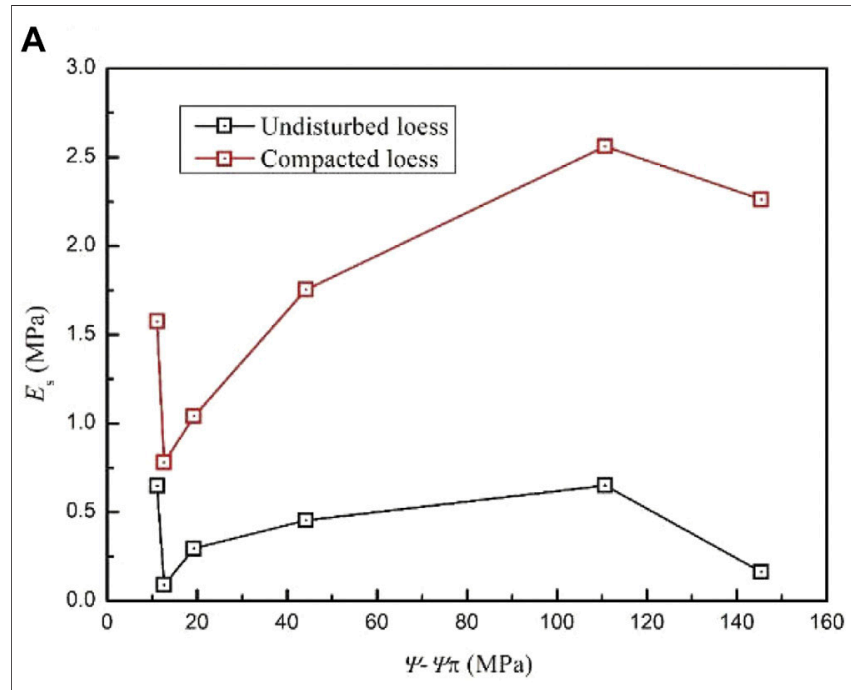

B

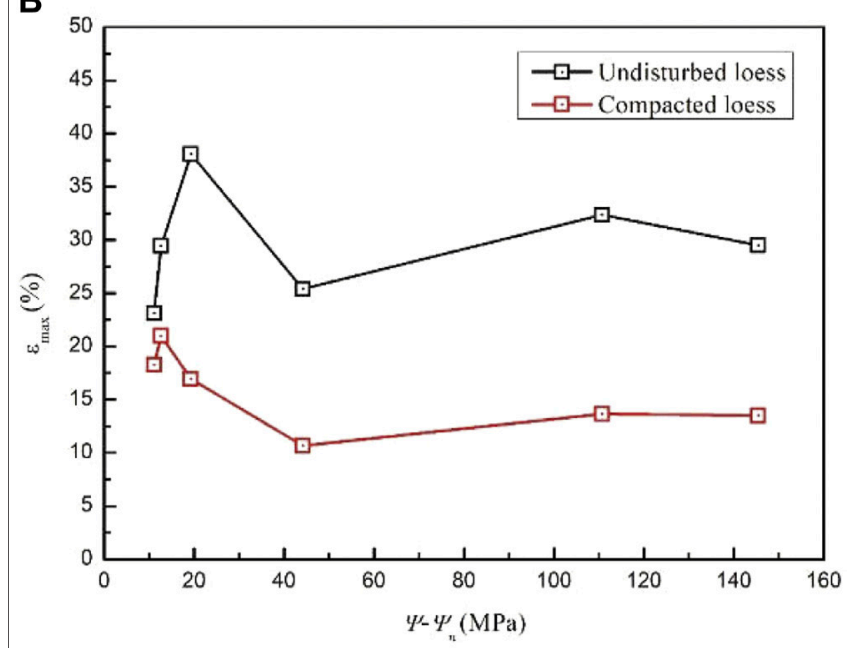

FIGURE 10 | The compression modulus and ultimate strain changed with $\Psi-\Psi_{\pi}$ : (A) $E_{\mathrm{S}}$ versus $\Psi-\Psi_{\pi}$; (B) $\varepsilon_{\max }$ versus $\Psi-\Psi_{\pi}$ 


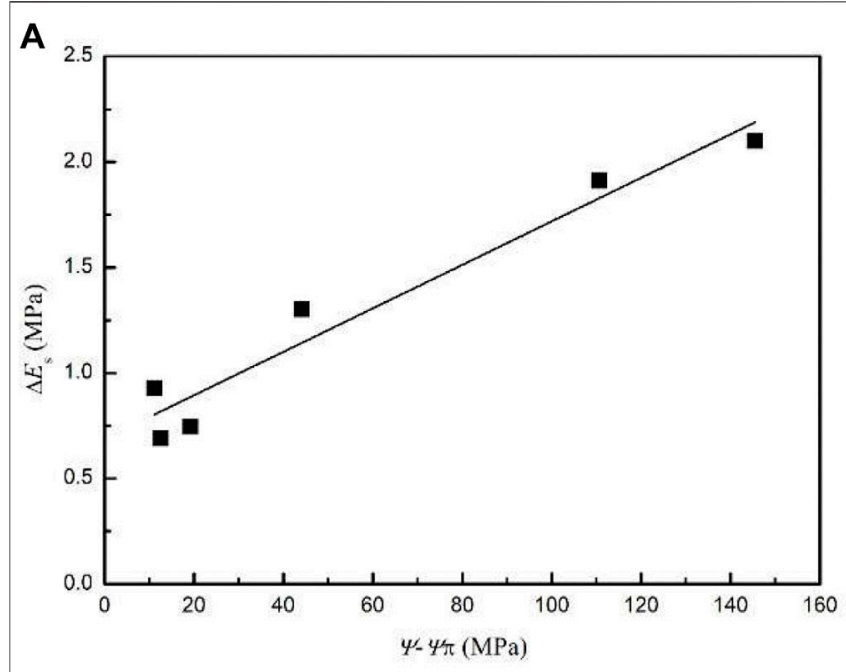

B

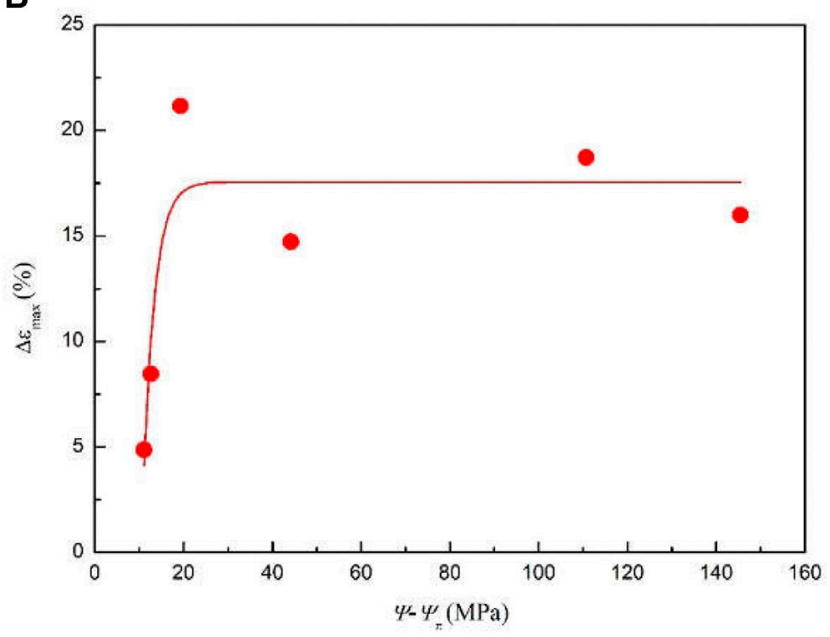

FIGURE 11 | The differences of compression parameters changed with $\Psi-\Psi_{\pi}$ : (A) $\Delta E_{\mathrm{S}}$ versus $\Psi-\Psi_{\pi}$; (B) $\Delta \varepsilon_{\max }$ versus $\Psi-\Psi_{\pi}$

$$
\varepsilon=\frac{p}{a+b p}
$$

Where $\varepsilon$ is the vertical strain of the specimen in one-dimensional compression test; $\mathrm{p}$ is vertical stress; $a$ and $b$ are the constant. The parameter $a$ is the reciprocal of the slope of the straight section at the initial stage of the curve, which is the compression modulus $E_{\mathrm{s}}$ $(\mathrm{MPa})$ under the lateral confining condition. The parameter $b$ is the reciprocal of the ultimate strain $\varepsilon_{\max }$ when the stress is infinite. As shown in Figure 9, the stress-strain relationships of soil were well described by Eq. 3 .

The key parameters $E_{\mathrm{s}}$ and $\varepsilon_{\max }$ in the above formula changed with $\Psi-\Psi_{\pi}$ were shown in Figure 10. As shown in Figure 10A, the trends of the two curves were similar and the initial $E_{\mathrm{s}}$ of compacted loess were higher than that of structural loess. The $E_{\mathrm{s}}$ generally increased with $\Psi-\Psi_{\pi}$, which indicated that the initial compression modulus was higher at lower ambient humidity corresponding to a dry state. While the $E_{\mathrm{s}}$ followed an inverse relationship in the range of $11-14 \mathrm{MPa}$ and $110-146 \mathrm{MPa}$. It could be attributed to the deliquescence and efflorescence of saline crystals and different pore water chemistry in soil. In the range of 11-14 $\mathrm{MPa}$, the crystals in soil deliquesced at high ambient humidity and the osmotic suction of intrusion liquid increased the applied chemistry loading. The maximum $E_{\mathrm{s}}$ at $\Psi$ $\Psi_{\pi}=110.7 \mathrm{MPa}$ was due to the efflorescence of crystals and increasing of solid phase volume. The results shown in Figure 10B indicated that $\varepsilon_{\max }$ of compacted loess regularly decreased with $\Psi-\Psi_{\pi}$ increasing due to the lower moisture content under high total suction. Due to the collapse of structural loess, the $\varepsilon_{\max }$ of undisturbed loess located above the curve of compacted loess. There existed a peak value at $\Psi_{\pi}$ $=0.74 \mathrm{MPa}$ and $\Psi=20.06 \mathrm{MPa}$, which corresponded to that the $\mathrm{NaCl}$ solution induced collapse under high ambient humidity $(R H>85 \%)$. It could be impacted by the coupling of initial pore structure and pore water chemistry.

To compare the influences of initial structure of loess, the $\Delta E_{\mathrm{s}}$ and $\Delta \varepsilon_{\max }$, which were the differences between the $E_{\mathrm{s}}$ or $\varepsilon_{\max }$ of structural loess and $E_{\mathrm{s}}$ or $\varepsilon_{\max }$ of compacted soil, were plotted in Figure 11. It is interesting that the relationship between $\Delta E_{\mathrm{s}}$ and $\Psi$ $\Psi_{\pi}$ subjected to a positive linear function as shown in Figure 11A. The results indicated that the elastoplastic modulus was significantly correlated to the $\Psi-\Psi_{\pi}$ without considering initial structure of loess under the water intrusion. The scattered data could be attributed to the clay particle flocculation resulted by the ion concentration increasing in pore water. In Figure 11B, the $\Delta \varepsilon_{\max }$ between the structural loess and compacted loess exponential increased with $\Psi-\Psi_{\pi}$, which indicated that samples with higher total suction would have a larger strain under the liquid intrusion. When the $R H$ decreased, the solution induced volume change became inert with the $\Psi-\Psi_{\pi}$.

Based on the above results, the different physical properties of compacted and undisturbed loess will lead to uneven settlement near the interface of filling and excavating area. In the engineering practice, the humidity and saline water intrusion should be considered in the long-term behavior of loess in shallow layer.

\section{The Mechanism of Total Suction and Osmotic Suction Effects}

Normally, the soil was considered as a three-phase material. The saline soil widely distributed in the arid area, and the salt crystals commonly existed between soil particles, composing the inter particle cementation and skeleton. Meanwhile, the dissolved salt in pore water would transform between the liquid phase and crystal in the solid phase under certain conditions. In the condition of relatively dry environment, the excessive salt will change from liquid phase to solid phase. During the upward migration of groundwater, precipitation infiltration or ambient humidity increasing, the salt crystals in the solid phase will change to liquid phase. Thus, the cementation would dissolve and the skeleton would collapse. The $\mathrm{NaCl}$ and $\mathrm{Na}_{2} \mathrm{SO}_{4}$ are two main salts in saline soil, which have a certain degree of deliquescence and moisture absorption capacity. In the process of environmental humidity change, their phase transform played a key role in the structure of loess. 


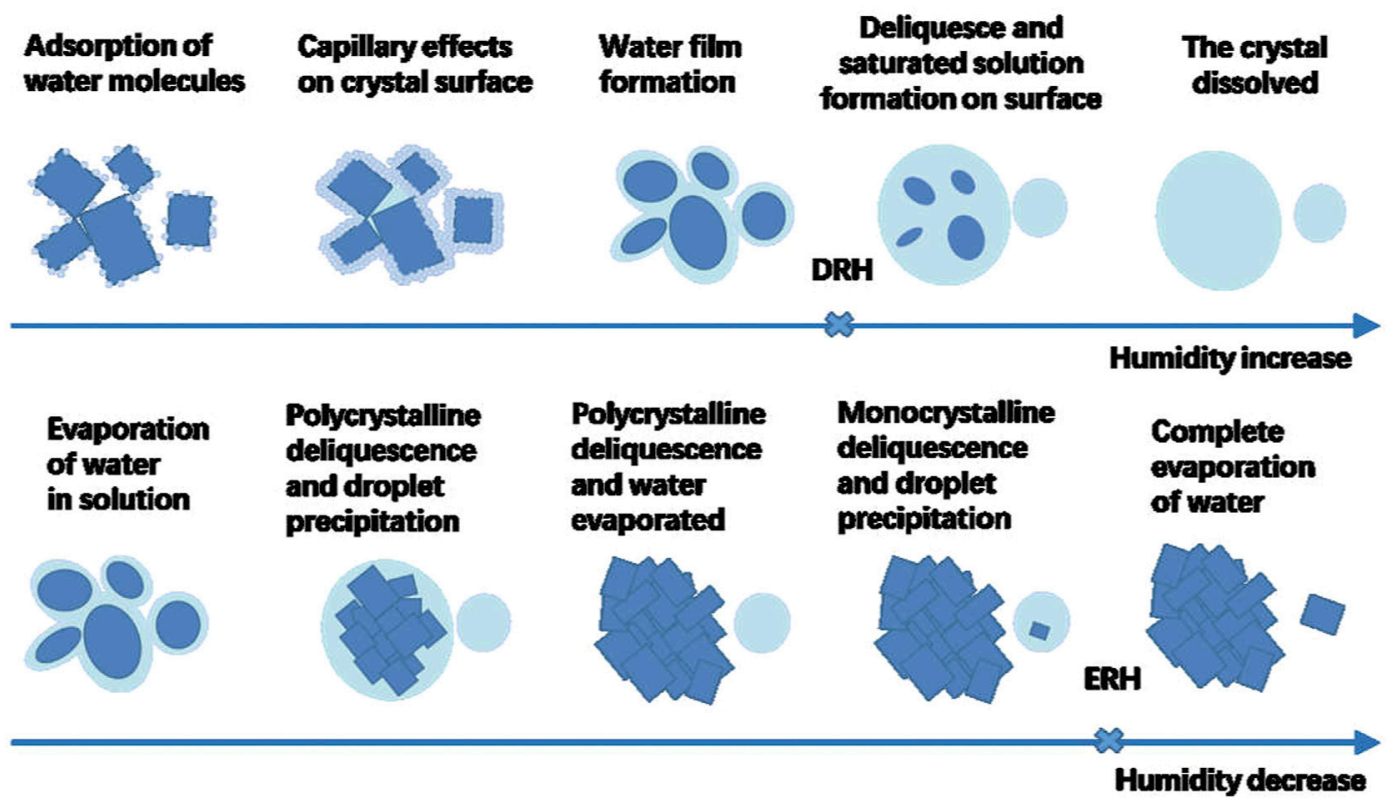

FIGURE 12 | The deliquescence and efflorescence under relative humidity change (Xu et al., 2020).

In recent years, many studies had obtained the variation rule of $\mathrm{NaCl}$ crystal deliquescence under environmental humidity changing (Zhang et al., 2012; Langlet et al., 2013). As shown in Figure 12, the deliquescence relative humidity (DRH) divided the deliquescence process of $\mathrm{NaCl}$ into two stages. When the ambient humidity was less than $\mathrm{DRH}$, the adsorption of water molecules by salt crystals was in term of physical adsorption. With the increase of humidity, water molecules continued to be absorbed and finally formed a water film on the surface of salt crystals. When the ambient humidity was higher than $\mathrm{DRH}$, the salt crystals will deliquesce, and further dissolve with the increase of humidity to form a saturated salt solution. After salt deliquescence, the cementation and skeleton of soil were weakened.

Different from the effects of deliquescence of sodium chloride on the deformation of undisturbed loess, the effects of sodium sulfate on undisturbed deformation were more complex. On one hand, with the increase of humidity, sodium sulfate hydrated with water molecules, resulting in a significant increase in crystal volume. This volume expansion process squeezed the pores, resulting in the loosening and destruction of the microstructure of the soil. On the other hand, a variety of salts in the soil lead to the decrease of DRH of sodium sulfate, and sodium sulfate dissolved to form a saturated solution. The DRH of $\mathrm{Na}_{2} \mathrm{SO}_{4}$ was about $96 \%$, which show that lower ambient humidity can not make it completely dissolved. When the humidity of the saturated solution of dissolved sodium sulfate decreased, the recrystallization process after efflorescence relative humidity (ERH) occurred. As shown in Figure 12, during recrystallization, sodium sulfate crystals resulted in a more dense structure of loess. That is the reason that compression parameters and creeping deformation fluctuated when $\mathrm{Na}_{2} \mathrm{SO}_{4}$ solution was involved.

\section{CONCLUSION}

In this paper, we developed an oedometer test to investigate the compression behavior of natural and compacted loess under environmental humidity (represented by total suction $\Psi$ ) and injection water salinity (represented by osmotic suction $\Psi_{\pi}$ ) changes. Based on the analysis of results, several conclusions were drawn:

1) The creeping of undisturbed and compacted loess under the ambient humidity changing, and the collapse under the coupling of total suction and saline water intrusion were nonnegligible. The volume changes of structural loess, whose initial void ratio was larger than 1.0 , were normally higher than that of compacted loess at above two stages. The differences between two loesses were 3-20 times.

2) Under the constant loading of $25 \mathrm{kPa}$ which represented the stresses in shallow layer, the creeping deformation of undisturbed loess significantly decreased with total suction increasing which corresponding to relative humidity decreasing. When the $R H<90 \%$, the $\Delta e$ at secondary consolidation stage were lower than 0.01 . While, the $\Delta e$ reached to 0.03 as the $R H=96 \%$. For the compacted loess, the $\Delta e$ at secondary consolidation stage were all lower than 0.01 and seemed to be irrelevant to environmental humidity. When the solution was induced, the collapse of undisturbed loess increased to 0.08 with the $\Psi-\Psi_{\pi}$ increasing. The difference under different humidity reached nearly 20 times. The higher $\Psi-\Psi_{\pi}$ resulted in a higher solution inducing collapse. While, the volume changes of compacted loess decreased with $\Psi-\Psi_{\pi}$ increasing, and that of samples were under 0.015 . 
3) In the $e-\lg p$ curves, the compression index $C_{c}$ of samples generally decreased with $\Psi-\Psi_{\pi}$, and the compressibility of undisturbed loess was higher. The swelling indices $C_{\mathrm{s}}$ of samples also decreased with $\Psi-\Psi_{\pi}$, but the variation was not significant. The reason for the higher $C_{c}$ of undisturbed and remolded loess under higher humidity is that the micro pores in soil absorbed water and moisture content increased. The soil cementation hydrated resulting in larger compressibility of structural loess.

4) In the stress-strain curves, the $E_{\mathrm{s}}$ generally increased with $\Psi$ $\Psi_{\pi}$, which indicated that the initial compression modulus was higher at lower ambient humidity. The maximum $E_{\mathrm{s}}$ at $\Psi-\Psi_{\pi}$ $=110.7 \mathrm{MPa}$ was due to the efflorescence of crystals and increasing of solid phase volume. The $\varepsilon_{\max }$ of compacted loess regularly decreased with $\Psi-\Psi_{\pi}$ increasing due to the lower moisture content under high total suction. Due to the collapse of structural loess, the $\varepsilon_{\max }$ of undisturbed loess located above the curve of compacted loess. It is interesting that the relationship between $\Delta E_{\mathrm{s}}$ (the differences between the structural loess and compacted loess) and $\Psi-\Psi_{\pi}$ subjected to a positive linear function. The $\Delta \varepsilon_{\max }$ between the structural loess and compacted loess exponential increased with $\Psi-\Psi_{\pi}$.

5) When the ambient humidity was higher than deliquescence relative humidity (DRH), the salt crystals will deliquesce, and further dissolve with the increase of humidity to form a saturated salt solution. After salt deliquescence, the cementation and skeleton of soil were weakened. When the humidity of the saturated solution of dissolved sodium sulfate decreased, the recrystallization process after efflorescence relative humidity (ERH) occurred. During recrystallization, sodium sulfate crystals resulted in a more dense structure of loess.

\section{REFERENCES}

Amir Akbari, G., Mohsen, H. S., Ahmadi, G., and Cherati, Y. D. (2018). Effect of Road Salts on the Hydro-Mechanical Behavior of Unsaturated Collapsible Soils. Transp. Geotech. 30143. doi:10.1016/j.trgeo.2018.09.005

Chang, Z., Gao, H., Huang, F., Chen, J., Huang, J., and Guo, Z. (2020). Study on the Creep Behaviours and the Improved Burgers Model of a Loess Landslide Considering Matric Suction. Nat. Hazards 103, 1479-1497. doi:10.1007/ s11069-020-04046-0

Chen, C., Zhang, D., and Zhang, J. (2017). Influence of Stress and Water Content on Air Permeability of Intact Loess. Can. Geotech J. 54, 1221-1230. doi:10.1139/ cgj-2016-0186

Daliakopoulos, I. N., Tsanis, I. K., Koutroulis, A., Kourgialas, N. N., Varouchakis, A. E., Karatzas, G. P., et al. (2016). The Threat of Soil Salinity: A European Scale Review. Sci. Total Environ. 573, 727-739. doi:10.1016/j.scitotenv.2016.08.177

Debora, J., and Miller, J. D. N. (2006). "Osmotic Suction in Unsaturated Soil Mechanics," in 2006 Fourth International Conference on Unsaturated Soils April, Carefree, Arizona, United States.

Deng, Y., Zhang, T., Cui, Y., Chen, Y., Deng, T., and Zhou, X. (2018). Pore Water Salinity Effect on the Intrinsic Compression Behaviour of Artificial Soft Soils. Appl. Clay Sci. 166, 299-306. doi:10.1016/j.clay.2018.09.027

Elkady, T. Y., and Al-Mahbashi, A. M. (2017). Effect of Solute Concentration on the Volume Change and Shear Strength of Compacted Natural Expansive clay. Environ. Earth Sci. 76. doi:10.1007/s12665-017-6825-0

He, Y., Ye, W. M., Chen, Y. G., Zhang, K. N., and Wu, D. Y. (2020). Effects of NaCl Solution on the Swelling and Shrinkage Behavior of Compacted Bentonite under One-Dimensional Conditions. B. Eng. Geol. Environ. 79, 399-410. doi:10. 1007/s10064-019-01568-1
Based on the above results, the different physical properties of compacted and undisturbed loess will lead to uneven settlement near the interface of filling and excavating area. In the engineering practice, the humidity and saline water intrusion should be considered in the long-term behavior of loess in shallow layer.

\section{DATA AVAILABILITY STATEMENT}

The raw data supporting the conclusions of this article will be made available by the authors, without undue reservation.

\section{AUTHOR CONTRIBUTIONS}

Plan and paper writing, TZ; Testing and data analysis, ZH; Plan and revision, HL; Discussion and revision, YD; Discussion and revision, $\mathrm{HZ}$.

\section{FUNDING}

This study was supported by the National Natural Science Foundation of China (Grant Nos. 42041006, 42090053, 41807225 and 41790443), the National Key Research and Development Program of China (2018YFC1504700), the China Postdoctoral Science Foundation (Grant Nos. 2019M653791), Natural Science Foundation of Gansu Province, China (Grant Nos. 20JR5RA259), Fundamental Research Funds for the Central Universities (Grant Nos. lzujbky-2020-pd08 and lzujbky-2021ct04).

Ivushkin, K., Bartholomeus, H., Bregt, A. K., Pulatov, A., Kempen, B., and de Sousa, L. (2019). Global Mapping of Soil Salinity Change. Remote Sens Environ. 231, 111260. doi:10.1016/j.rse.2019.111260

Jabar, M., and Rasul, G. S. G. M. (2017). The Effect of Wetting and Drying on the Performance of Stabilized Subgrade Soils. Transp. Geotech. 30122-8. doi:10. 1016/j.trgeo.2017.09.002

Koniorczyk, M., and Gawin, D. (2008). Heat and Moisture Transport in Porous Building Materials Containing Salt. J. Build Phys. 31, 279-300. doi:10.1177/ 1744259107088003

Lan, H., Zhao, X., Macciotta, R., Peng, J., Li, L., Wu, Y., et al. (2021). The Cyclic Expansion and Contraction Characteristics of a Loess Slope and Implications for Slope Stability. Sci. Rep. 11, 2250. doi:10.1038/s41598-021-81821-4

Langlet, M., Benali, M., Pezron, I., Saleh, K., Guigon, P., and Metlas-Komunjer, L. (2013). Caking of Sodium Chloride: Role of Ambient Relative Humidity in Dissolution and Recrystallization Process. Chem. Eng. Sci. 86, 78-86. doi:10. 1016/j.ces.2012.05.014

Loret, B., Hueckel, T., and Gajo, A. (2002). Chemo-mechanical Coupling in Saturated Porous media: Elastic-Plastic Behaviour of Homoionic Expansive Clays. Int. J. Sol. Struct. 39, 2773-2806. doi:10.1016/s0020-7683(02)00151-8

Ma, F., Jing, Y., and Xiao-hong, B. (2016). Water Sensitivity and Microstructure of Compacted Loess. Transp. Geotech., 11, 41-56. doi:10.1016/j.trgeo.2017.03.003

$\mathrm{Mu}, \mathrm{Q}$. Y., Zhou, C., and Ng, C. W. W. (2020). Compression and Wetting Induced Volumetric Behavior of Loess: Macro- and Micro-investigations. Transp. Geotech. 23, 100345. doi:10.1016/j.trgeo.2020.100345

Ng, C. W., and Pang, Y. W. (2000). Experimental Investigations of the Soil-Water Characteristics of a Volcanic Soil. Can. Geotech J. 6, 1252-1264. doi:10.1139/t00-056

Niu, X., and Yao, Y. (2021). Resilient Modulus experiment of Subgrade Soil on Different Wetting-Drying and Salt Washing-Supplying Paths. Transp. Geotech. 28, 100512. doi:10.1016/j.trgeo.2021.100512 
Qin, P., Liu, Y., Song, Z., Ma, F., and Dong, X. (2020). An Electrical Resistivity Method of Characterizing Hydromechanical and Structural Properties of Compacted Loess during Constant Rate of Strain Compression. Sensors 20, 4783. doi:10.3390/s20174783

Sato, M., and Hattanji, T. (2018). A Laboratory experiment on Salt Weathering by Humidity Change: Salt Damage Induced by Deliquescence and Hydration. Prog. Earth Planet. Sci. 5, 84. doi:10. 1186/s40645-018-0241-2

Wang, P., Ye, Y., Zhang, Q., Liu, J., and Yao, J. (2020). Investigation on the Sulfate Attack-Induced Heave of a Ballastless Track Railway Subgrade. Transportation Geotechnics. 23, 100316. doi:10.1016/j.trgeo.2020.100316

Wei, Y., Fan, W., Yu, B., Deng, L., and Wei, T. (2020). Characterization and Evolution of Three-Dimensional Microstructure of Malan Loess. Catena 192, 104585. doi:10.1016/j.catena.2020.104585

Wen, B., and Yan, Y. (2014). Influence of Structure on Shear Characteristics of the Unsaturated Loess in Lanzhou, China. Eng. Geol. 168, 46-58. doi:10.1016/j. enggeo.2013.10.023

Witteveen, P., Ferrari, A., and Laloui, L. (2013). An Experimental and Constitutive Investigation on the Chemo-Mechanical Behaviour of a clay. Geotechnique 63, 244-255. doi:10.1680/geot.sip13.p.027

Xu, J., Li, Y., Ren, C., and Lan, W. (2020). Damage of saline Intact Loess after DryWet and its Interpretation Based on SEM and NMR. Soils Found. 60, 911-928. doi:10.1016/j.sandf.2020.06.006

Zhang, F., Wang, G., Kamai, T., Chen, W., Zhang, D., and Yang, J. (2013). Undrained Shear Behavior of Loess Saturated with Different Concentrations of Sodium Chloride Solution. Eng. Geol. 155, 69-79. doi:10.1016/j.enggeo.2012. 12.018

Zhang, F., Ye, W. M., Chen, Y.-G., Chen, B., and Cui, Y.-J. (2016). Influences of Salt Solution Concentration and Vertical Stress during Saturation on the Volume
Change Behavior of Compacted GMZ01 Bentonite. Eng. Geol. 207, 48-55. doi:10.1016/j.enggeo.2016.04.010

Zhang, H., Yan, G., and Wang, X. (2012). Laboratory Test on Moisture Adsorption-Desorption of wall Paintings at Mogao Grottoes, China. J. Zhejiang Univ-sc. A. 13, 208-218. doi:10.1631/jzus.a1100204

Zhang, T., and Wang, S. (2019). Explanation of the Influence of Sodium Chloride Solution on Volume Deformation and Permeability of Normally Consolidated Clays. Materials 12, 1671. doi:10.3390/ma12101671

Zuo, L., Xu, L., Baudet, B. A., Gao, C., and Huang, C. (2020). The Structure Degradation of a Silty Loess Induced by Long-Term Water Seepage. Eng. Geol. 272, 105634. doi:10.1016/j.enggeo.2020.105634

Conflict of Interest: The authors declare that the research was conducted in the absence of any commercial or financial relationships that could be construed as a potential conflict of interest.

Publisher's Note: All claims expressed in this article are solely those of the authors and do not necessarily represent those of their affiliated organizations, or those of the publisher, the editors and the reviewers. Any product that may be evaluated in this article, or claim that may be made by its manufacturer, is not guaranteed or endorsed by the publisher.

Copyright (C) 2022 Zhang, Hu, Lan, Deng and Zhang. This is an open-access article distributed under the terms of the Creative Commons Attribution License (CC BY). The use, distribution or reproduction in other forums is permitted, provided the original author(s) and the copyright owner(s) are credited and that the original publication in this journal is cited, in accordance with accepted academic practice. No use, distribution or reproduction is permitted which does not comply with these terms. 